\title{
MINING HIGH VALUE TRAVELERS USING A NEW MODEL DESIGNED FOR ONLINE CRM SYSTEMS: A CASE STUDY IN TAIWAN
}

\author{
Wen-Yu CHIANG \\ Department of Air Transportation Management, Aletheia University, \\ 70-11 Pei-Shi-Liao, Matou, 721 Tainan, Taiwan \\ E-mail: ianc888@gmail.com
}

Received 14 August 2013; accepted 20 August 2014

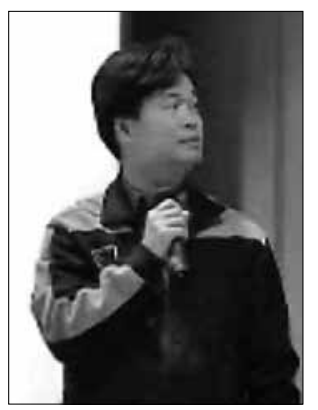

\author{
Wen-Yu CHIANG, PhD \\ Education: PhD degree, the National Taiwan Ocean University, the Faculty of Shipping \\ and Transportation Mgt., Specialization: marketing management. \\ Affiliations: 2005 - to present, Assistant Prof., Aletheia University, the Department of Air \\ Transportation Management. \\ Research interests: data mining technologies with an emphasis on businesses. \\ Publications: author of 16 social science articles, 4 science articles, and 3 conference papers.
}

\begin{abstract}
The purpose of this research is to investigate the mining of high value travelers for online travel agencies. For the research the AHP (analytic hierarchy process) procedure was applied with a new model of customer value on a database (RFM model based). In this article, the customer values of online travelers can be analyzed via a proposed equation (FMLC-CV), and the travelers can be ranked via a proposed FMLC model and the AHP procedure. According to the research logic, high value travelers can be discovered in the travelers' database. Through the value ranking the value markets can be clustered according to value scores as well. The results can be applied to online CRM systems to help the travel industry realize the high value markets of travelers, and implement various marketing plans for different markets.
\end{abstract}

Keywords: AHP procedure, RFM model, FMLC-CV equation, FMLC model, CRM systems.

\section{Introduction}

The purpose of this research is to investigate the mining of high value markets for the industry of online travel agencies. The procedure of this study can assist businesses in reaching customer values from their customer relationship management (CRM) systems automatically and effectively.

Hence, this study employs the AHP procedure and proposes a new FMLC model (RFM model based) to create markets ranked according to high customer values. Customer value variables are usually profit variables for businesses (Kotler, Keller 2006; Chiang 2012). Based on the RFM model (Roberts 1992; Goodman 1992; Hughes 1994), businesses can create their customer value variables according to their operational methods (Chiang 2012).

The proposed FMLC model consists of four variables: Frequency, Monetary, Low price / Discount pro- ducts and Cancellation times (RFM model based). These four variables are the most effective and suitable for realizing customer values in the industry of online travel agencies (Chiang 2012).

\section{Literature review}

The RFM model was proposed by A. M. Hughes (1994) and in his study variable $\mathrm{R}$ (recency) was defined as "the last purchasing time in a specific period"; variable $\mathrm{F}$ (frequency) was defined as "the purchasing frequency in a specific period"; and variable M (monetary) was defined as "the average amount of purchasing in a specific period".

The RFM model was applied in a study analyzing sport-store members (Lo et al. 2008). The results of this research indicate that shoppers of high customer value in this field were male, and aged between 26 and 35 . 
Research has also been carried out on the weight estimation of the RFM model, for instance (Shih, Liu 2003) applied the AHP (Analytic Hierarchy Process) to obtain the weights of the RFM model. They found eight high customer value clusters via the weights that were found for the RFM model.

The Analytic Hierarchy Process (AHP) was introduced by T. L. Saaty (1971) and it was developed as another way to structure decision analysis. The AHP procedure can be employed for obtaining weights of factors. The AHP procedure can be applied to RFM markets for ranking markets with RFM weights. For instance, Y. Y. Shih and C. Y. Liu (2003) applied the AHP (Analytic Hierarchy Process) for obtaining the weights of the RFM model. They found eight high customer value clusters and two types of important customers via the weights obtained for the RFM model. X. Weiwen et al. (2008) applied the AHP procedure with RFM markets to a logistics enterprise to segment their ten customers. They found that the weighted RFM markets were effective for the segmentation.

The RFM model can be applied for marketing segmentation as well. For instance, C. S. Lin and Y. Q. Tang (2006), W. Y. Chiang (2011) adopted the RFM model to distinguish customers into several markets. They divided each of the RFM variables into two levels: high $(\mathrm{H})$ and low (L), which resulted in markets LLL, LLH, LHH, LHL, HLL, HLH, HHL and HHH respectively.

The RFM model can be associated with the segmentation analysis applied to business systems. For instance, C. H. Cheng and Y. S. Chen (2009) applied the RFM model with a K-means clustering algorithm to mine rules for CRM systems. Besides, S. C. Huang et al. (2009) applied bagged clustering, K-means, and Fuzzy C-means, respectively, together with the RFM model. They found that bagged clustering is superior to the other two methods.

For research in the field of market segmentation based on the RFM model, C. H. Cheng and Y. S. Chen (2009) used the RFM variables on the K-means algorithm and rough set theory to mine accuracy classification rules. These rules can be applied in CRM systems of enterprises. As for the research involving Fuzzy clustering and the RFM model, S. C. Huang et al. (2009) applied the K-means method, the Fuzzy C-means clustering method, the RFM model, and the bagged clustering algorithm to analyse the customer value for an outfitter in Taipei. Their study concluded that the bagged clustering algorithm was better than the others.

Additionally, the RFM model can be employed for market segmentation for finding some valuable customers (Goodman 1992). The RFM model can be revised for a specific industry as well. For example, W. Y. Chiang (2013) add the Discount variable to the RFM model, so that the model is improved to become a FMDT model (D for Discount; T for staying Time). W. Y. Chiang dis- covered useful rules for the coffee shops industry via the FMDT model, and some rules have been established for discovering the markets of coffee shop clients in Taiwan.

As for the analysis of customer value, for instance, J. Y. Wong and P. H. Chung (2007) adopted the RFM model and a decision tree algorithm to analyze Taiwan's domestic airline markets. Their research discovered customer values for each of the domestic routes. The domestic airlines of Taiwan can implement their marketing plans to these routes (markets). Their study will help domestic airlines to enhance the growth rates of passengers.

Advances have been made to improve the RFM model: W. Y. Chiang (2009) developed the RFM model into the RFMDT model ( $\mathrm{D}$ variable for discount; $\mathrm{T}$ variable for shopping times within six months) and some decision rules were created for marketing projects of online retailers. In his study, the research objectives were experienced online shoppers in Taiwan.

\section{Methodology}

\subsection{Research logic}

The research logic of this study can be applied to the development of online CRM systems. CRM systems are complex systems with feedback loops (Stair, Reynolds 2008). As figure 1 shows, the transactional records can be transferred from POS systems, where ranked high value travelers are the target markets. The research applies a revised model of customer value - FMLC (which is composed of the following variables: frequency, monetary, low price / discount products, and cancellation times) to segment this market. The customer value markets are established via the FMLC variables (RFM model based) which can mine the valuable target markets for the industry of online travel agencies (Tan et al. 2005).

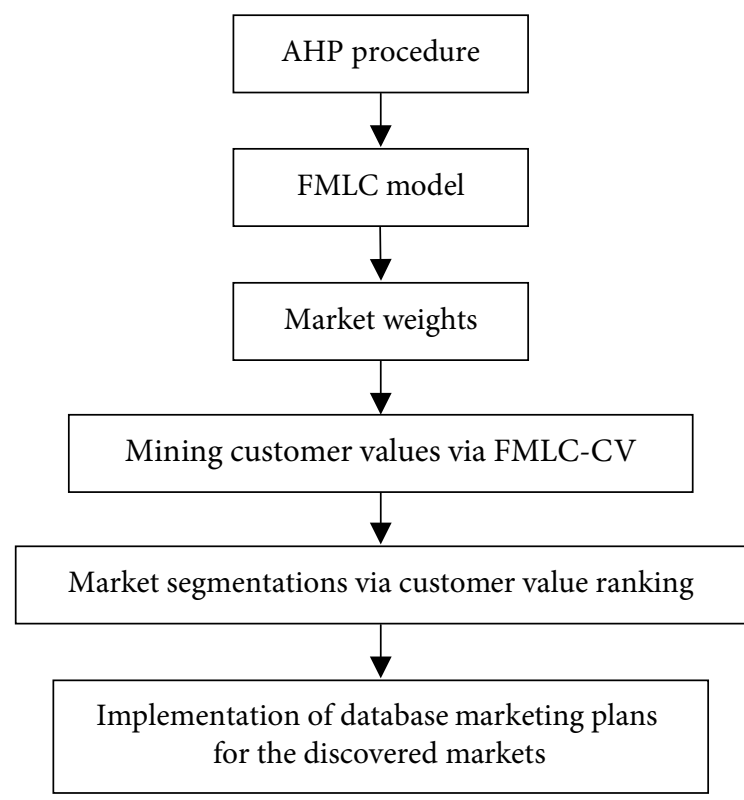

Fig.1. Research logic 


\subsection{FMLC model, AHP procedure and FMLC-CV equation}

The AHP steps for the FMLC model are as follows:

1. Design the FMLC model as an AHP pair-wise comparison matrix.

2. Get the AHP matrix filled in by three experts and three scholars in the online shopping field.

3. Compute the consistence index (C.I. $=\frac{\lambda-n}{n-1}$ ). 4. Compute the consistency ratio (C.R. $=\frac{\text { C.I. }}{\text { R.I. }}$
R.I. is a random index)

5. The R.I. is illustrated as a table (Table 1) below.

Table 1. Random index table (Saaty 1977)

\begin{tabular}{l|llllllllll}
\hline $\mathrm{n}$ & 1 & 2 & 3 & 4 & 5 & 6 & 7 & 8 & 9 & 10
\end{tabular}

\begin{tabular}{l|lllllllllll} 
R. I. & 0.00 & 0.00 & 0.58 & 0.90 & 1.12 & 1.24 & 1.32 & 1.41 & 1.45 & 1.49 \\
\hline
\end{tabular}

The researcher discussed the profit variables of online travel agencies in March, 2013 with three scholars and three experts in the field of online shopping. The discussion results permit to conclude that the Frequency, Monetary, Low price/Discount products, and Cancellation time variables (FMLC model; RFM model based) are the most effective and suitable for realizing customer values in the industry of online travel agencies (Chiang 2012). The discussion results allowed defining the shopping period for calculations as well. The present research adopts the AHP (analytic hierarchy process, Saaty 1971) to calculate the FMLC variable weights. Thus, the equation is formulated as follows:

$$
F M L C-C V=F^{\star} W 1+M^{\star} W 2-L^{\star} W 3-C^{\star} W 4,(1)
$$

where: $F$ is frequency; $M$ - monetary; $L$ - low price/ discount; $C$ - cancellation times; $W 1$ - market weight of $F$ variable; $W 2$ - market weight of $M$ variable; $W 3$ market weight of $L$ variable; $W 4$ - market weight of $C$ variable.

The values of $F, M, L$ and $C$ can be input from the customer transactions' database. The weight values of $W 1, W 2, W 3$ and $W 4$ can be computed via an AHP spreadsheet's matrix sheet (section 4). Hence, the $F$ and $M$ variables are positive profit variables for calculating the customer value; the $L$ and $C$ variables are negative profit values for calculating the customer value (Chiang 2014).

\section{Results}

The weights of FMLC variables are computed by using an AHP spreadsheet's matrix sheet. The results show that the consistency index (C.I) equals 0.0639 and the random index (R. I., where the $\mathrm{n}=4, \mathrm{n}$ is number of elements) is 0.90 . Thus, the consistency ratio (C.R. = C.I. / R.I.) is 0.071. T. L. Saaty (1977) suggested that 'the consistency ratio is fine when the C. R. value is smaller than 0.1 '.
Thus, the consistency ratio of the FMLC variable for estimating online travelers is fine. As for the FMLC variable weights, they are: $F-28.5 \%, M-19.7 \%, L-$ $26.3 \%$, and $C-25.5 \%$, respectively. Therefore, according to the FMLC variable weights, their levels of importance should be $F>L>C>M$.

The study proposes an equation for the estimation of the customer value of online travelers. According to the FMLC variable weights obtained through the AHP procedure, the weights are substituted into the FMLC-CV equation. Thus, the customer values of online travelers can be obtained.

The FMLC variable weights are: $W 1-28.5 \%, W 2-$ $19.7 \%, W 3-26.3 \%$, and $W 4-25.5 \%$, respectively. These weights are substituted into the following equation: $F M L C-C V=F^{\star} W 1+M^{\star} W 2-L^{\star} W 3-C^{\star} W 4$.

Hence, the equation with weights included is: $F M L C-C V=F^{\star} 28.5 \%+M{ }^{*} 19.7 \%-L^{\star} 26.3 \%-C^{\star} 25.5 \%$, where $F, M, L$, and $C$ indicate Frequency, Monetary, Low price/Discount products, and Cancellation times, respectively. The $F$ and $M$ are positive benefit variables (positive contributions to businesses), and the $L$ and $C$ variables are negative benefit variables (Chiang 2012).

\section{Conclusions and suggestions}

The proposed new FMLC model and equation were applied to the database of an online travel agency. The model can be described as follows:

1. $\mathrm{F}$ is defined as the "frequency of shopping times in the last year";

2. $\mathrm{M}$ is defined as the "monetary of shopping amount in the last year";

3. $\mathrm{L}$ is defined as the "percentage of low price or discount travel products relative to the total amount in the last year";

4. $\mathrm{C}$ is defined as the "cancellation times in the last year".

In order to explain the proposed model and equation, the researcher has employed an online database of a travel agency in Taiwan as a case study (in period from Jan., 2013 to Jun., 2013). 168 customer records were discovered in the mentioned period. The records are shown in table 2. The values illustrated in table 2 have been computed using the FMLC-CV equation for the travelers. For example, the customer values for S. C. Huang, C. S. Lin, and Y. S. Chen travelers are 159.248, 198.091 and 236.9248, respectively. Thus, compared to travelers S. C. Huang and C. C. Lin, Y. S. Chen has a higher customer value. Travel agencies can, therefore, identify the values of the customers in the database. According to the discovered customer value, travel agencies may implement various marketing plans in CRM systems for attracting travelers of various ranges of customer values. The equation is formulated as follows: $F M L C-C V=F^{\star} 28.5 \%+M^{*} 19.7 \%-L^{\star} 26.3 \%-C^{\star} 25.5 \%$. 
Table 2. Samples of FMLC-CV customer values

\begin{tabular}{|c|l|c|c|c|c|c|l|}
\hline $\begin{array}{c}\text { ID } \\
\#\end{array}$ & $\begin{array}{c}\text { Air } \\
\text { Travelers }\end{array}$ & $\mathrm{F}$ & $\mathrm{M}$ & $\mathrm{L}$ & $\mathrm{C}$ & $\begin{array}{c}\text { Customer } \\
\text { Values }\end{array}$ & Ranking \\
\hline 1 & S. C. Huang & 7 & 800 & $35 \%$ & 1 & 159.2480 & 3 \\
\hline 2 & C. S. Lin & 5 & 1000 & $30 \%$ & 1 & 198.0910 & 2 \\
\hline 3 & Y. S. Chen & 4 & 1200 & $40 \%$ & 2 & 236.9248 & 1 \\
\hline
\end{tabular}

$F$ - frequency, $M$ - monetary, $L$ - low / discount price,

$C$ - cancellation times.

Table 2 illustrates that traveler Y. S. Chen has a higher customer value than travelers C. S. Lin and S. C. Huang. So, the travelers can be easily sorted by using their customer values. Online travel agencies can apply the new model and equation to their CRM system databases to obtain customer values. Using this technique online travel agencies can realize high value, middle, or low value markets. Hence, online travel agencies can have different marketing plans for each market. In this study, three value markets have been discovered via customer values. As figure 2 shows, the customer values of the highest market are $>200$, the middle value market is between 100 and 199, and the last market is $<100$. Online travel agencies can define the markets according to their experiences. For example, online travel retailers can implement a one-to-one marketing plan (Linoff, Berry 2002) for the highest market (customer values $>200$ ), or for the middle level market (customer values between 100 and 199).

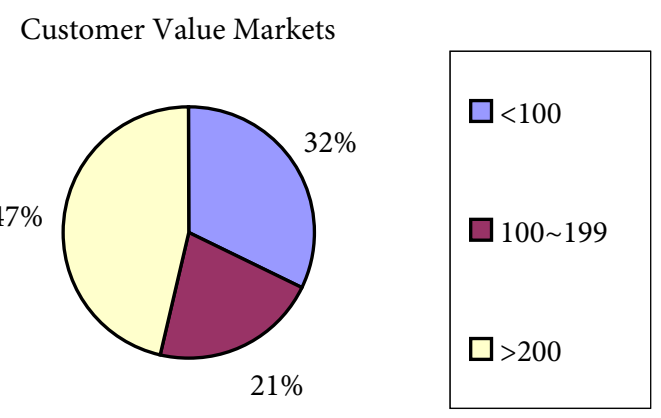

Fig. 2. Customer value markets for an online travel agency in Taiwan, 2013 (Jan. Jun.)

To conclude, the systems of online travel agencies can automatically modify customer values via daily updated shopping transactions. Thus, according to the discovered ranking and markets, it will be easier for online travel agencies to plan their CRM systems or marketing projects for travelers' markets.

\section{References}

Cheng, C. H.; Chen, Y. S. 2009. Classifying the segmentation of customer value via RFM model and RS theory, Expert Systems with Applications 36(3): 4176-4184. http://dx.doi.org/10.1016/j.eswa.2008.04.003

Chiang, W. Y. 2011. To mine association rules of customer values via a data mining procedure with improved model: an empirical case study, Expert Systems with Applications 38(3): 1716-1722. http://dx.doi.org/10.1016/j.eswa.2010.07.097
Chiang, W. Y. 2012. Applying a new model of customer value on international air passengers' market in Taiwan, International Journal of Tourism Research 14(2): 116-123. http://dx.doi.org/10.1002/jtr.840

Chiang, W. Y. 2013. Applying data mining on customer relationship management system for leisure coffee-shop industry: a case study in Taiwan, WIREs Data Mining Knowledge Discovery 3(2): 129-139.

http://dx.doi.org/10.1002/widm.1084

Chiang, W. Y. 2014. Applying data mining with a new model on customer relationship management systems: a case of airline industry in Taiwan, Transportation Letters: the International Journal of Transportation Research 6(2): 89-97. http://dx.doi.org/10.1179/1942787514Y.0000000014

Goodman, J. 1992. Leveraging the customer database to your competitive advantage, Direct Marketing 55(8): 26-27.

Huang, S. C.; Chang, E. C.; Wu, H. H. 2009. A case study of applying data mining techniques in an outfitter's customer value analysis, Expert System with Applications 36(6): 59095915. http://dx.doi.org/10.1016/j.eswa.2008.07.027

Hughes, A. M. 1994. Strategic database marketing. Chicago, IL: Probus Publishing.

Kotler, P.; Keller, K. L. 2006. Marketing management. $12^{\text {th }}$ ed. New York, NY: Pearson Education Inc.

Lin, C. S.; Tang, Y. Q. 2006. Application of incremental mining and customer's value analysis to collaborative music recommendations, Journal of Information, Technology and Society 6(1): 1-26.

Linoff, G. S.; Berry, M. J. A. 2002. Mining the web: transforming customer data into customer value. Jersey City, NJ: John Wiley and Sons Inc.

Lo, C. F.; Wu, H. H.; Chang, E. C., et al. 2008. Applying data mining to an outfitter's customer loyalty, and value analysis, Journal of Quality 15(4): 293-303.

Roberts, M. L. 1992. Expanding the role of the direct marketing database, Journal of Direct Marketing 6(2): 51-60. http://dx.doi.org/10.1002/dir.4000060208

Saaty, T. L. 1971. How to make a decision: the analytic hierarchy process, European Journal of Operational Research 40: 9-10.

Saaty, T. L. 1977. A scaling method for priorities in hierarchical structure, Journal of Mathematical Psychology 15(3): 234-281. http://dx.doi.org/10.1016/0022-2496(77)90033-5

Shih, Y. Y.; Liu, C. Y. 2003. A method for customer lifetime value ranking-combining the analytic hierarchy process and clustering analysis, Journal of Database Marketing and Customer Strategy Management 11(2): 159-172. http://dx.doi.org/10.1057/palgrave.dbm.3240216

Stair, R. M.; Reynolds, G. W. 2008. Fundamentals of information systems: a managerial approach. 4 th ed. Boston, Mass.: Thomson Course Technology.

Tan, P. N.; Steinbach, M.; Kumar, V. 2005. Introduction to data mining. Boston, Mass.: Pearson Addison Wesley.

Weiwen, X.; Liang, C.; Zhiyong, Z., et al. 2008. RFM value and grey relation based customer segmentation model in the logistics market segmentation, in Proceedings of the $5^{\text {th }}$ International Conference on Computer Science and Software Engineering, 12-14 December 2008, Wuhan, Hubey, 1298-1301.

Wong, J. Y.; Chung, P. H. 2007. Managing valuable Taiwanese airline passengers using knowledge discovery in database techniques, Journal of Air Transportation Management 13(6):362-370.

http://dx.doi.org/10.1016/j.jairtraman.2007.07.001 